\title{
Evolução da Produtividade Total dos Fatores na Economia Brasileira com Ênfase no Capital Humano - 1992-2007*
}

\author{
Fernando de Holanda Barbosa Filho ${ }^{\dagger}$, Samuel de Abreu Pessôa ${ }^{\ddagger}$, \\ Fernando A. Veloso ${ }^{\S}$
}

Conteúdo: 1. Introdução; 2. Metodologia; 3. Resultados; 4. Análise de Oferta e Demanda; 5. Conclusão.

Palavras-chave: Crescimento Econômico, Produtividade Total dos Fatores, Capital Humano.

Códigos JEL: $\quad$ 047, J24, J31.

Este artigo investiga a evolução da produtividade total dos fatores (PTF) para a economia brasileira no período de 1992 a 2007, utilizando uma medida de capital humano baseada em dados microeconômicos. Uma das principais contribuições deste artigo é a construção de uma medida específica de capital humano que permite mensurar tanto a evolução da participação dos diversos níveis de escolaridade e experiência do trabalhador no total de horas trabalhadas como a variação em sua produtividade ao longo do tempo. Os resultados mostram que a PTF teve um crescimento de apenas 11,3\% entre 1992 e 2007, contribuindo com cerca de $22,9 \%$ do crescimento do PIB verificado no período. Outro resultado importante é que o capital humano da força de trabalho no Brasil manteve-se virtualmente estacionário durante o período sob análise. Isto ocorreu devido ao fato da elevação do componente de participação do capital humano ter sido compensada por uma redução do componente de produtividade. Por último, mostra-se que o aumento da oferta de trabalho qualificado é o fator que explica a queda da remuneração do capital humano. Em particular, a necessidade de mão-de-obra mais qualificada não parece ter imposto uma restrição ao crescimento da economia, já que sua oferta cresceu em ritmo superior à demanda.

\footnotetext{
* Os autores agradecem os comentários de Almir Bittencourt, Carlos Eugênio da Costa, participantes do Encontro CAEN/EPGE de 2009, do XXXVI Encontro da Anpec, dos seminários da EPGE, do IPEA e do INSPER. Fernando Veloso agradece o apoio financeiro do CNPq. Erros remanescentes são de total responsabilidade dos autores.

${ }^{\dagger}$ Centro de Desenvolvimento Econômico (CDE) do Instituto Brasileiro de Economia da Fundação Getulio Vargas (IBRE-FGV). E-mail: fhbf@fgv . br

${ }^{\ddagger}$ Centro de Desenvolvimento Econômico (CDE) do Instituto Brasileiro de Economia da Fundação Getulio Vargas (IBRE-FGV).

$\S$ IBMEC Rio de Janeiro (Ibmec RJ).
} 
This paper investigates the evolution of total factor productivity (TFP) for the Brazilian economy between 1992 and 2007, using a measure of human capital based on microeconomic data. One of the main contributions of this paper is to construct a specific measure of human capital that allows one to quantify both the evolution of the participation of the different levels of education and experience of the labor force in total hours worked and the variation of its productivity over time. The results show that TFP increased only 11.3\% between 1992 and 2007 and accounted for about 22.9\% of the growth rate of GDP in the period. Another important result is that the human capital of the labor force in Brazil was almost stationary during the period. This was due to the fact that the increase in the participation component of the labor force was compensated by the reduction in the productivity component. Finally, it is shown that the increase in the supply of more educated workers explains the decline in human capital compensation. In particular, the lack of a better educated labor force does not appear to have imposed a restriction to economic growth, since its supply increased faster than the demand.

\section{INTRODUÇÃO}

Este artigo investiga a evolução da produtividade total dos fatores (PTF) para a economia brasileira no período de 1992 a 2007, utilizando uma medida de capital humano construída a partir de dados microeconômicos. Também é realizada uma decomposição de crescimento do PIB da economia brasileira para o mesmo período, com o objetivo de mensurar a importância de cada um dos seus componentes: capital físico, capital humano, número de horas trabalhadas e PTF.

Diversos estudos analisaram o comportamento da produtividade total dos fatores no Brasil nas últimas décadas, incluindo Bonelli e Fonseca (1998), Silva Filho (2001), Pinheiro et alii (2001) e Bugarin et alii (2004). Em geral, estes artigos encontram uma taxa de crescimento negativa para a produtividade total dos fatores na década de 1980 , e uma significativa elevação da taxa de crescimento da PTF na década de 1990.

No entanto, esses estudos não incluem o capital humano dentre os fatores de produção. Como mostram Topel (1999), Krueger e Lindahl (2001) e Lange e Topel (2006), o capital humano agregado tem um efeito significativo no crescimento econômico, de magnitude não inferior ao efeito microeconômico da educação sobre os salários. Essa literatura evidencia a importância de incluir o capital humano na análise de decomposições de crescimento.

Gomes et alii (2003) analisam a evolução da PTF no Brasil entre 1950 e 2000, utilizando uma medida de capital humano construída com base na formulação de Bils e Klenow (2000). Os autores mostram que, devido à elevação da escolaridade média da força de trabalho no Brasil na década de 1990, o aumento da PTF nesse período foi consideravelmente menor que o encontrado em estudos que não incluem o capital humano dentre os fatores de produção. ${ }^{1}$ No entanto, a formulação em Gomes et alii (2003), como usual nesta literatura, apresenta a limitação de mensurar o capital humano a partir de um indicador predominantemente quantitativo, baseado nos anos médios de escolaridade da população economicamente ativa (PEA). ${ }^{2}$

\footnotetext{
${ }^{1}$ Esses resultados foram confirmados em Ferreira et alii (2008).

${ }^{2}$ Ver, por exemplo, Hall e Jones (1999). Bils e Klenow (2000) utilizam também indicadores de experiência da força de trabalho. Esses estudos procuram levar em conta o impacto da escolaridade no capital humano através de uma estimativa da taxa de
} 
Uma das principais contribuições do presente artigo refere-se à construção de uma medida específica de capital humano, que mensura tanto a evolução da participação dos diversos níveis de escolaridade e experiência do trabalhador no total de horas trabalhadas, como a variação em sua produtividade ao longo do tempo. Essa decomposição é possível porque a medida de capital humano utilizada nesse estudo é construída com o auxílio de uma regressão de Mincer (1974) de salários, em que o capital humano é obtido através da produtividade marginal do trabalho. Em particular, o artigo mostra que essa medida de capital humano decorre naturalmente da agregação das equações de Mincer individuais para todos os trabalhadores. A base de dados utilizada para o cálculo do capital humano e do número de horas trabalhados é a Pesquisa Nacional por Amostra de Domicílios (PNAD) do IBGE.

Uma medida de capital humano que consiga distinguir produtividade de quantidade é especialmente importante quando investiga-se um período no qual a produtividade do capital humano está variando fortemente, como provavelmente tem se verificado no Brasil nas últimas décadas. O forte esforço de universalizar o acesso à educação, após descaso secular, faz com que a nova clientela da escola pública venha de lares com background familiar pior em comparação ao período no qual o acesso era muito restrito. Adicionalmente, a elevação da cobertura não contou com a elevação de orçamento nem com a adaptação gerencial requerida. Todos estes fatores sugerem que a elevação da medida de capital humano proposta neste artigo deve, em princípio, ser menor do que a obtida com o emprego de um conceito puramente quantitativo baseado, por exemplo, nos anos médios de escolaridade da PEA.

Os resultados mostram que a PTF teve um crescimento de apenas 11,3\% entre 1992 e 2007, contribuindo com cerca de $22,9 \%$ do crescimento do PIB verificado no período. Outro resultado importante é que o capital humano da força de trabalho no Brasil manteve-se virtualmente estacionário durante o período sob análise. Isto ocorreu devido ao fato da elevação do componente de participação do capital humano ter sido compensada por uma redução do componente de produtividade.

0 trabalho também apresenta uma análise de oferta e demanda por capital humano para identificar qual fator explica a dinâmica da remuneração do capital humano entre 1992 e 2007, utilizando uma metodologia baseada em Katz e Murphy (1992). Os resultados indicam que alterações na oferta de trabalho comandaram a dinâmica da variação da remuneração do capital humano no período, indicando que a oferta cresceu em ritmo superior ao da demanda.

O artigo está organizado em quatro seções, além desta Introdução. A Seção 2 apresenta a metodologia utilizada na análise, incluindo o procedimento de construção da variável de capital humano. Ainda nesta seção, apresentamos o método de decomposição do crescimento do produto e o método de decomposição do capital humano em seus componentes de participação e produtividade. A Seção 3 apresenta os resultados obtidos sobre produtividade e capital humano. A Seção 4 apresenta a análise de oferta e demanda de trabalho para explicar a dinâmica na remuneração do capital humano. As principais conclusões do artigo estão reunidas na Seção 5.

\section{METODOLOGIA}

\subsection{Função de produção}

A função de produção é dada por $Y_{t}=A_{t} F\left(u_{t} K_{t}, H_{t} L_{t}\right)$ em que $Y_{t}$ é o produto agregado, $A_{t}$ é a produtividade total dos fatores (PTF), $u_{t}$ é o índice de utilização da capacidade instalada (NUCI), $K_{t}$ é o estoque de capital físico disponível na economia, $u_{t} K_{t}$ é o total de serviços produtivos do capital utilizado na produção, $H_{t}$ é o capital humano por trabalhador e $L_{t}$ é o número de horas agregado.

A função de produção utilizada nesse artigo é dada pela especificação Cobb-Douglas:

$$
Y_{t}=A_{t}\left(u_{t} K_{t}\right)^{\alpha}\left(H_{t} L_{t}\right)^{1-\alpha}
$$

retorno da educação. No entanto, esta é obtida com base em dados de uma cross-section de países. Em consequência, a evolução do capital humano em cada país ao longo do tempo reflete predominantemente a variação da escolaridade média. 
em que $\alpha$ é a elasticidade do produto em relação ao capital, a qual é igual à participação do capital na renda em equilíbrio competitivo. Neste artigo, vamos supor $\alpha=0,4$, com base em Gomes et alii (2003). A condição de maximização do lucro das firmas com respeito ao trabalho, e tecnologia descrita por (1), implica que o salário por hora trabalhada é proporcional ao capital humano por trabalhador:

$$
w=w_{0} H,
$$

onde $w$ é o salário real de um trabalhador com capital humano $H$ e $w_{0}$ é o salário de um trabalhador sem qualificação.

\subsection{Capital humano e horas trabalhadas}

O cálculo do capital humano por trabalhador, $H_{t}$, considera diferenças entre os trabalhadores em termos de escolaridade, $h_{t}$, e de experiência, $E_{t}$. A amostra foi dividida em cinco níveis de escolaridade: analfabetos e com $1^{\circ}$ ciclo do ensino fundamental incompleto (inferior a quatro anos de estudo), $1^{o}$ ciclo do ensino fundamental completo (escolaridade igual ou maior que quatro e inferior a oito anos de estudo), $2^{\circ}$ ciclo do ensino fundamental completo (igual ou maior que oito e inferior a onze anos de estudo), ensino médio completo (igual ou maior que onze e inferior a quinze anos de estudo) e superior completo (quinze ou mais anos de estudo). Os níveis de experiência foram divididos em intervalos de cinco anos: de 0 a 4 anos de experiência, de 5 a 9 anos de experiência, de 10 a 14 anos de experiên$\mathrm{cia}^{3}$, e assim sucessivamente até indivíduos com experiência superior a 30 anos. O cruzamento das cinco categorias de escolaridade com as sete categorias de experiência produz 35 categorias do par escolaridade-experiência.

A medida de capital humano tem dois componentes: a produtividade e a participação. Diversos estudos que investigam a relação entre educação e crescimento econômico mostram que o impacto agregado do capital humano no produto é de magnitude similar ao efeito microeconômico da educação sobre os salários. ${ }^{4}$ Em função disso, neste artigo a produtividade é compreendida como o retorno que o mercado de trabalho paga a uma dada combinação de escolaridade e experiência, enquanto a participação é interpretada como o peso relativo de cada grupo de escolaridade e experiência no total de horas trabalhadas.

Para obter a produtividade, $\beta_{j k}\left(h_{j}, E_{k}\right)$, de um trabalhador com $h_{j}$ anos de educação e $E_{k}$ anos de experiência, estimaremos uma equação de Mincer onde são consideradas 35 variáveis dummies com a interação entre os diversos níveis de escolaridade e experiência. Estas dummies foram estimadas com base na seguinte equação de Mincer, em que $w_{i}$ é o salário por hora do $i$-ésimo trabalhador:

$$
\ln w_{i}=\alpha_{0}+\sum_{j=1}^{5} \sum_{k=1}^{7} \beta_{j k}\left(h_{j, i}, E_{k, i}\right) \psi_{j k}\left(h_{j, i}, E_{k, i}\right)+\sum_{l=1}^{I} \gamma_{l} \operatorname{controles}_{l, i}+\varepsilon_{i}
$$

Na equação, $\psi_{j k}$ representa cada uma das 35 dummies associadas às interações entre experiência e escolaridade e $\beta_{j k}$ é o seu coeficiente, que representa o retorno associado ao par $(j, k)$ de escolaridade e experiência. O coeficiente $\gamma_{l}$ é o retorno dos controles utilizados na regressão.

Definindo o salário médio $w$ como a média geométrica ponderada dos salários individuais, onde os pesos $\varphi_{i}$ são dados pela participação do $i$-ésimo trabalhador na oferta total de trabalho, temos:

$$
w=\prod_{i=1}^{N} w_{i}^{\varphi_{i}}
$$

\footnotetext{
${ }^{3}$ A variável experiência é definida como: $E=($ idade $)-($ anosdeestudo $)-6$.

${ }^{4}$ Ver Topel (1999), Krueger e Lindahl (2001) e Lange e Topel (2006). Barbosa Filho e Pessôa (2008) apresentam um survey da literatura.
} 
Sob a hipótese de que há $i=1, \ldots, N$ trabalhadores e que cada trabalhador tenha trabalhado $l_{i}$ horas, temos de (3) e (4) que o logaritmo do salário médio por hora pode ser escrito como:

$$
\ln w=\frac{\sum_{i=1}^{N} l_{i} \ln w_{i}}{\sum_{i=1}^{N} l_{i}}=\alpha_{0}+\frac{\sum_{i=1}^{N} \sum_{j=1}^{5} \sum_{k=1}^{7} l_{i} \beta_{j k} \psi_{j k}}{\sum_{i=1}^{N} l_{i}}+\frac{\sum_{i=1}^{N} \sum_{l=1}^{I} l_{i} \gamma_{l} \text { controles }_{l, i}}{\sum_{i=1}^{N} l_{i}}
$$

A equação (5) pode ser reescrita como:

$$
\ln w=\alpha_{0}+\sum_{j=1}^{5} \sum_{k=1}^{7} \frac{\sum_{i=1}^{N} l_{i} \beta_{j k} \psi_{j k}}{\sum_{i=1}^{N} l_{i}}+G
$$

em que

$$
G=\frac{\sum_{i=1}^{N} \sum_{l=1}^{I} l_{i} \gamma_{l} \text { controles }_{l, i}}{\sum_{i=1}^{N} l_{i}}
$$

Assim,

$$
\ln w=\alpha_{0}+\sum_{j=1}^{5} \sum_{k=1}^{7} \beta_{j k} \varphi_{j k}+G
$$

em que $\varphi_{j k}$ é a participação na oferta total do trabalho da categoria de capital humano que combina 0 $j$-ésimo tipo de escolaridade e a $k$-ésima modalidade de experiência, $j=1, \ldots, 5$, e $k=1, \ldots, 7$, isto é:

$$
\varphi_{j k}=\frac{\sum_{i=1}^{N} l_{i} \psi_{j k}}{\sum_{i=1}^{N} l_{i}}
$$

A equação (6) pode ser reescrita como:

$$
w=w_{0} \prod_{j=1}^{5} \prod_{k=1}^{7}\left(e^{\beta_{j k}\left(h_{j, i}, E_{k, i}\right)}\right)^{\varphi_{j k}}
$$

onde $w_{0}=e^{\alpha_{0}+G}$. De (2) e (7), a agregação das equações mincerianas individuais é compatível com o comportamento maximizador das firmas desde que o capital humano seja expresso como:

$$
H=\prod_{j=1}^{5} \prod_{k=1}^{7}\left(e^{\beta_{j k}\left(h_{j, i}, E_{k, i}\right)}\right)^{\varphi_{j k}}
$$

Neste artigo, utilizaremos a medida de capital humano descrita por (8). O total de horas trabalhadas na economia é obtido através da soma do total de horas trabalhadas de cada grupo.

$$
L=\sum_{j=1}^{5} \sum_{k=1}^{7} l_{j k}
$$

Com isso, podemos calcular a participação, $\varphi_{j k}$, no total de horas trabalhadas de cada um dos 35 grupos de trabalhadores com $h$ anos de escolaridade e $E$ anos de experiência.

Os dados foram obtidos da Pesquisa Nacional de Amostra Domiciliar (PNAD) para todos os anos no período 1992-2007. Foram utilizados dados para homens e mulheres com idade entre 16 e 65 anos. As regressões de salários foram estimadas por mínimos quadrados ordinários, sendo utilizados os pesos amostrais de cada observação. Foram empregadas as seguintes variáveis de controle: dummies de sexo, cor, trabalhador sindicalizado, trabalhador do setor público e trabalhador com carteira. 
O capital humano de uma economia pode estar alocado no setor público ou privado, e a medida de capital humano aqui utilizada busca medir o valor do capital humano independente do setor onde este atua. Desta forma, é importante não computar como retorno do capital o prêmio de salário existente no setor público. Neste sentido, utiliza-se na estimação dos retornos do capital humano, $\beta_{j k}\left(h_{j, i}, E_{k, i}\right)$, uma dummy para o setor público.

Como o objetivo deste artigo é mensurar a PTF agregada da economia, a separação do capital humano em público e privado só seria interessante caso fosse possível a separação do produto e dos outros fatores de produção: capital fisico e horas trabalhadas. A separação das horas trabalhadas e do produto pode ser feita com base na PNAD e nas contas nacionais respectivamente, mas a separação do capital físico é tarefa complicada.

\subsection{Estoque de capital físico}

O estoque de capital físico é calculado com base no método do inventário perpétuo, dado por:

$$
K_{t+1}=(1-\delta) K_{t}+I_{t}
$$

em que $K_{t}$ é o nível de capital no período $t, K_{t+1}$ é o nível de capital do período seguinte, $\delta$ é a taxa de depreciação e $I_{t}$ é o investimento.

Para obter uma série de capital é necessário que se possua um nível de capital inicial, uma taxa de depreciação e o investimento da economia para cada período. Para calcularmos o estoque de capital inicial, assumimos que a relação capital-produto em 1970 era de 2,36, com base em Gomes et alii (2003). Também utilizamos o valor da taxa de depreciação do capital físico empregada nesse estudo, igual a 3,5\%. Os dados de investimento foram obtidos da série de Formação Bruta de Capital Fixo a preços constantes do Sistema de Contas Nacionais (SCN) do IBGE. O estoque de capital foi ajustado pelo grau de utilização da capacidade, $u_{t}$, obtido a partir de dados da Confederação Nacional da Indústria (CNI).

\subsection{Decomposição do crescimento}

Esta subseção tem como objetivo descrever a forma utilizada para mensurar como cada um dos fatores que afetam o produto, PTF, capital fisico, capital humano e trabalho, contribuiu para o crescimento do PIB em diversos intervalos de tempo do período analisado. Com base em (1), a decomposição do produto entre os instantes $t$ e $t+N$ pode ser descrita da seguinte forma:

$$
\begin{aligned}
\frac{1}{N} \ln \left(\frac{Y_{t+N}}{Y_{t}}\right) & =\frac{1}{N}\left\{\ln \left(\frac{A_{t+N}}{A_{t}}\right)+\alpha \ln \left(\frac{u_{t+N} K_{t+N}}{u_{t} K_{t}}\right)+(1-\alpha)\left[\ln \left(\frac{H_{t+N}}{H_{t}}\right)\right.\right. \\
& \left.\left.+\ln \left(\frac{L_{t+N}}{L_{t}}\right)\right]\right\}
\end{aligned}
$$

\subsection{Decomposição do capital humano}

A variação do capital humano pode ser decomposta em dois fatores: a produtividade, $\beta_{j k}$, e a participação, $\varphi_{j k}$. Com base na expressão do capital humano, pode-se decompor a taxa de crescimento do capital humano entre dois períodos consecutivos da seguinte forma: 


$$
\begin{aligned}
\ln \frac{H_{t}}{H_{t-1}} & =\ln \frac{\prod_{j=1}^{5} \prod_{k=1}^{7}\left(e^{\beta_{j k, t}\left(h_{j, i}, E_{k, i}\right)}\right)^{\varphi_{j k, t}}}{\prod_{j=1}^{5} \prod_{k=1}^{7}\left(e^{\beta_{j k, t-1}\left(h_{j, i}, E_{k, i}\right)}\right)^{\varphi_{j k, t-1}}} \\
& =\ln \prod_{j=1}^{5} \prod_{k=1}^{7}\left(e^{\beta_{j k, t}\left(h_{j, i}, E_{k, i}\right)}\right)^{\varphi_{j k, t}}-\ln \prod_{j=1}^{5} \prod_{k=1}^{7}\left(e^{\beta_{j k, t-1}\left(h_{j, i}, E_{k, i}\right)}\right)^{\varphi_{j k, t-1}} \\
& =\sum_{j=1}^{5} \sum_{k=1}^{7} \beta_{j k, t} \varphi_{j k, t}-\sum_{j=1}^{5} \sum_{k=1}^{7} \beta_{j k, t-1} \varphi_{j k, t-1}=\sum_{j=1}^{5} \sum_{k=1}^{7}\left(\beta_{j k, t} \varphi_{j k, t}-\beta_{j k, t-1} \varphi_{j k, t-1}\right)
\end{aligned}
$$

Esta expressão pode ser reescrita como:

$$
\begin{aligned}
& \ln \frac{H_{t}}{H_{t-1}}=\sum_{j=1}^{5} \sum_{k=1}^{7}\left(\beta_{j k, t} \varphi_{j k, t}-\beta_{j k, t-1} \varphi_{j k, t-1}\right)= \\
& \frac{1}{2} \sum_{j=1}^{5} \sum_{k=1}^{7}\left(\beta_{j k, t} \varphi_{j k, t}-\beta_{j k, t-1} \varphi_{j k, t-1}\right)+\frac{1}{2} \sum_{j=1}^{5} \sum_{k=1}^{7}\left(\beta_{j k, t} \varphi_{j k, t}-\beta_{j k, t-1} \varphi_{j k, t-1}\right) \\
& =\sum_{j=1}^{5} \sum_{k=1}^{7}\left\{\begin{array}{l}
\frac{1}{2}\left[\varphi_{j k, t}\left(\beta_{j k, t}-\beta_{j k, t-1}\right)+\beta_{j k, t-1}\left(\varphi_{j k, t}-\varphi_{j k, t-1}\right)\right]+ \\
+\frac{1}{2}\left[\varphi_{j k, t-1}\left(\beta_{j k, t}-\beta_{j k, t-1}\right)+\beta_{j k, t}\left(\varphi_{j k, t}-\varphi_{j k, t-1}\right)\right]
\end{array}\right\} \\
& =\sum_{j=1}^{5} \sum_{k=1}^{7}\left[\frac{\varphi_{j k, t}+\varphi_{j k, t-1}}{2}\left(\beta_{j k, t}-\beta_{j k, t-1}\right)+\frac{\beta_{j k, t}+\beta_{j k, t-1}}{2}\left(\varphi_{j k, t}-\varphi_{j k, t-1}\right)\right] \\
& =\sum_{j=1}^{5} \sum_{k=1}^{7} \frac{\varphi_{j k, t}+\varphi_{j k, t-1}}{2}\left(\beta_{j k, t}-\beta_{j k, t-1}\right)+ \\
& +\sum_{j=1}^{5} \sum_{k=1}^{7} \frac{\beta_{j k, t}+\beta_{j k, t-1}}{2}\left(\varphi_{j k, t}-\varphi_{j k, t-1}\right) \\
& \equiv \ln \frac{H_{t}^{\text {produtividade }}}{H_{t-1}^{\text {produtividade }}}+\ln \frac{H_{t}^{\text {participação }}}{H_{t-1}^{\text {participação }}}
\end{aligned}
$$

Como mostra (12), pode-se decompor a variação do capital humano em dois componentes, produtividade e participação, onde o primeiro captura a variação do retorno do capital humano entre dois períodos, e o segundo está associado à variação da participação de cada nível de capital humano no total de horas trabalhadas. 0 componente de produtividade pondera a variação do retorno pela média aritmética da participação, $\varphi$, no início e no fim do período em questão. Analogamente, o componente de participação utiliza como pesos os valores da produtividade, $\beta$, no início e no fim do período em questão.

A Figura 1 mostra a decomposição do capital humano calculado com base na metodologia apresentada. Nesta podemos perceber que o componente participação do capital humano aumentou ao longo do tempo, indicando uma política de universalização da educação no Brasil. Ao mesmo tempo, pode-se perceber que o componente de produtividade oscila bastante ao longo do tempo. Isto ocorre porque o componente de produtividade é fortemente afetado pelo ciclo econômico, visto que os salários variam 
junto com o nível de atividade da economia. Logo, pode-se perceber que a variação na medida de capital humano utilizada neste artigo decorre da variação dos salários com o ciclo econômico, que afeta o componente de produtividade.

Figura 1: Capital humano e sua decomposição

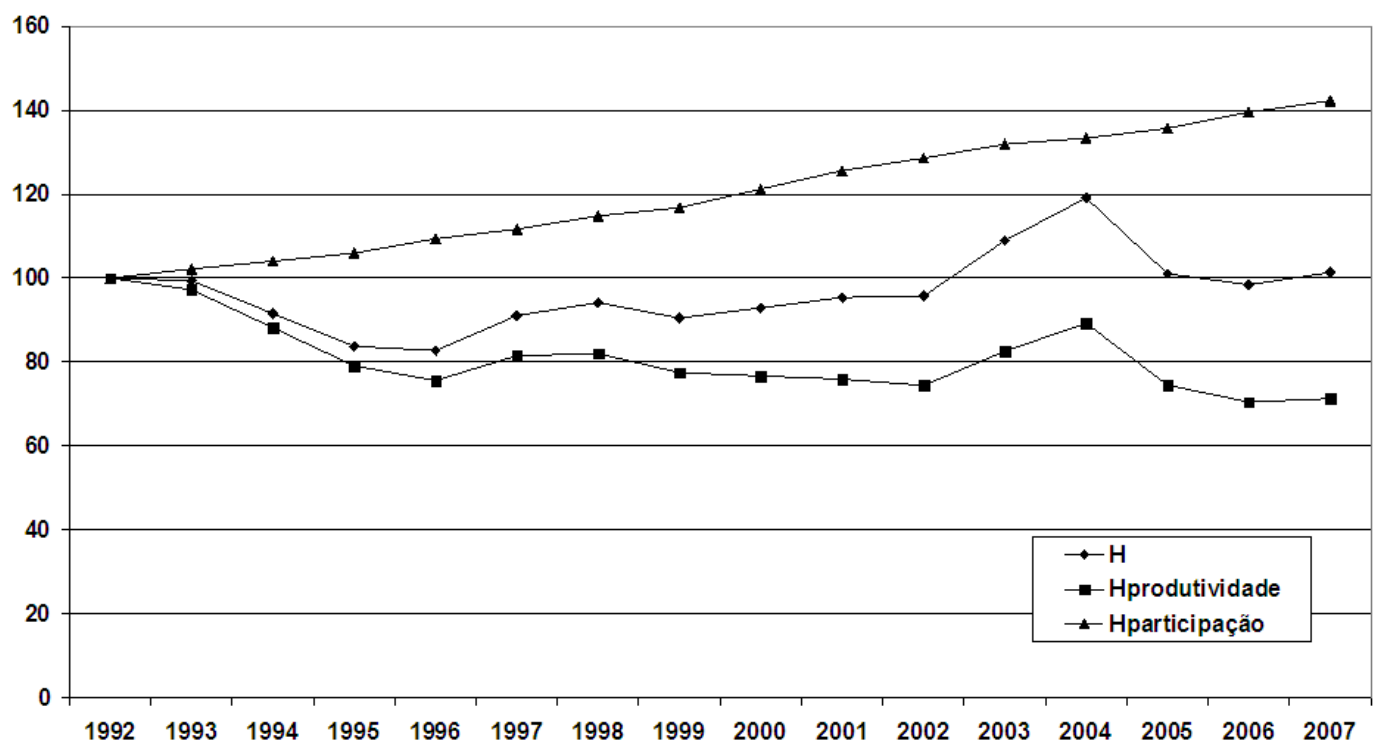

Devido à forma de cálculo do capital humano utilizada neste trabalho, que inclui anos de escolaridade e experiência, é possível quantificar a influência de cada variável na variação do capital humano de determinado período. Para tal, é necessário calcular os efeitos marginais de cada nível de escolaridade, para todas as experiências e, também, o efeito marginal de cada nível de experiência, para todas as escolaridades.

A penúltima linha da equação (12) apresenta, no primeiro somatório, o impacto da variação da produtividade e, no segundo somatório, o impacto da variação da participação no capital humano. Para identificar o efeito marginal da educação e da experiência em cada um destes componentes basta realizar, para cada uma das duas somatórias, uma soma parcial nos níveis de educação (efeito marginal da experiência) e nos anos de experiência (efeito marginal da educação). Ou seja, em vez de realizar o somatório nas 35 células (5 níveis de educação vezes os 7 níveis de experiência), realiza-se a soma somente em uma destas dimensões, experiência (sete) ou educação (cinco). Assim sendo, o efeito marginal da educação na produtividade, $E f M g E d P R$, é obtido da seguinte forma:

$$
\operatorname{EfMgEdPR} R_{j}=\sum_{k=1}^{7} \frac{\varphi_{j k, t}+\varphi_{j k, t-1}}{2}\left(\beta_{j k, t}-\beta_{j k, t-1}\right)
$$

em que $j$ é o nível educacional, $k$ é o nível de experiência e $\beta$ e $\varphi$ são os componentes de produtividade e participação. 
Por sua vez, o efeito marginal da experiência na produtividade, $E$ f $M g E x p P R$, é obtido da seguinte forma:

$$
\operatorname{EfMgExpPR} R_{k}=\sum_{j=1}^{5} \frac{\varphi_{j k, t}+\varphi_{j k, t-1}}{2}\left(\beta_{j k, t}-\beta_{j k, t-1}\right)
$$

em que $j$ é o nível educacional, $k$ é o nível de experiência e $\beta$ e $\varphi$ são os componentes de produtividade e participação.

Para obter o efeito marginal da educação e da experiência sobre a participação, devemos realizar o mesmo procedimento para a variação no componente de participação. Para isto, basta substituir $\beta$ e $\varphi$ nas equações.

Desta forma, temos:

$$
\begin{gathered}
\operatorname{EfMgEdPart}_{j}=\sum_{k=1}^{7} \frac{\beta_{j k, t}+\beta_{j k, t-1}}{2}\left(\varphi_{j k, t}-\varphi_{j k, t-1}\right) \\
\text { EfMgExpPart }_{k}=\sum_{j=1}^{5} \frac{\beta_{j k, t}+\beta_{j k, t-1}}{2}\left(\varphi_{j k, t}-\varphi_{j k, t-1}\right)
\end{gathered}
$$

\section{RESULTADOS}

\subsection{Evolução da produtividade total dos fatores}

Com base nas séries de PIB $^{5}$, capital físico, capital humano e horas trabalhadas construídas na seção anterior, calculamos a PTF da economia brasileira para o período 1992-2007. A Figura 2 mostra a evolução da PTF entre 1992 e 2007. Os resultados mostram que a PTF teve um crescimento de apenas 11,3\% no período 1992-2007. Esta evolução pode ser dividida em períodos com diferentes características. Primeiro, pode-se observar o rápido crescimento da PTF entre 1992 e 1996. Entre 1996 e 2002, observa-se uma queda da PTF, que se acentua no biênio 2003-2004. Por fim, a PTF apresenta um rápido crescimento entre 2004 e 2007.

Conforme mencionado na introdução, a maior parte da literatura de contabilidade do crescimento no Brasil não introduz o capital humano como um fator na função de produção. A Figura 3 permite comparar a medida de PTF utilizada nesse artigo com a medida de PTF obtida sem a inclusão do capital humano na função de produção. Nesse último caso, a PTF incluirá a contribuição do capital humano para o crescimento.

Como mostra a Figura 3, quando o capital humano não é incluído na função de produção, o comportamento da PTF torna-se consideravelmente mais estável. Embora o crescimento da PTF entre 1992 e 2007 tenha sido similar para as duas medidas, existem diferenças expressivas em alguns subperíodos. Em particular, o crescimento da PTF utilizando a medida que inclui o capital humano na função de produção foi bem maior nos subperíodos 1992-1996 e 2004-2007.

A Figura 3 mostra a PTF calculada sem capital humano e com o capital humano calculado com a metodologia sugerida neste artigo. Nesta pode-se perceber que a medida de PTF com capital humano apresenta uma maior variação do que a medida sem capital humano.

A PTF é uma medida do resíduo, ou seja, é a porção do produto não explicada pelo capital físico, capital humano e pela quantidade de horas trabalhadas. Desta forma, a medida de PTF apresentada neste artigo é mais volátil devido à forma de mensuração do capital humano, medido a preço de mercado, em vez de a preço de livro, como é medida a série de capital físico. Como o salário depende diretamente

\footnotetext{
${ }^{5} \mathrm{~A}$ série utilizada é a do produto interno bruto (PIB) a preços constantes do sistema de contas nacionais (SCN) do IBGE.
} 
Figura 2: Produtividade total dos fatores

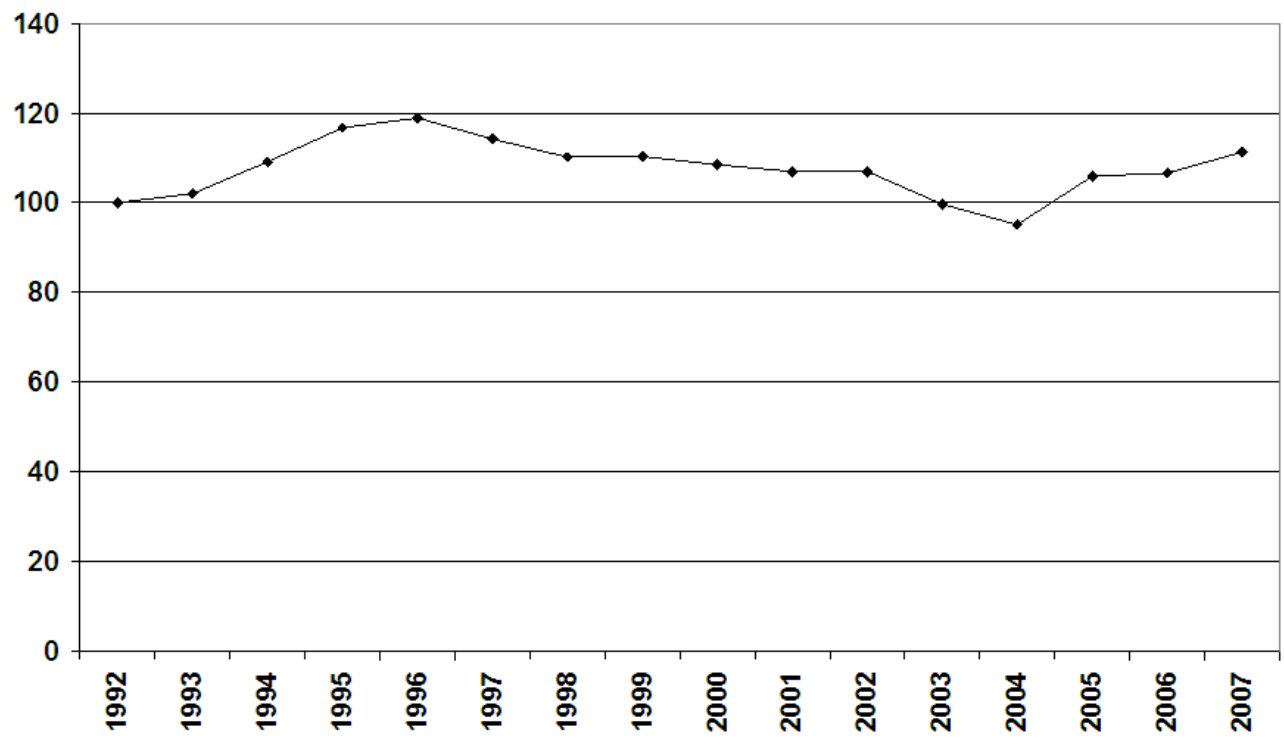

do ciclo econômico, o componente de produtividade do capital humano oscila bastante, como pode ser visto na Figura 1, elevando a volatilidade do capital humano em nossa amostra e, por consequência, adicionando volatilidade na PTF.

Conforme mostrado na Seção 2, o capital humano $(H)$ é composto por dois componentes, participação e produtividade. O componente de participação pouco varia com o ciclo. Entretanto, o componente de produtividade sofre forte influência do ciclo, uma vez que é obtido com base no retorno marginal do trabalho, determinado pela estimação dos coeficientes da regressão minceriana. Logo, em anos em que o retorno do trabalho sobe, o componente de produtividade aumenta, o que eleva os fatores e, para um dado nível de produto, reduz a PTF.

Além de medir a PTF com e sem capital humano na função de produção, a mesma pode ser calculada levando-se em conta somente um destes componentes do capital humano, o componente de participação. A Figura 4 apresenta as 3 diferentes medidas de PTF utilizadas: PTF, PTF sem H (capital humano) e a PTF com H participação (somente com o componente de participação do capital humano).

Como mostra a Figura 4, a medida de PTF que inclui somente o componente de participação do capital humano teve um comportamento estável entre 1992 e 1997, e sofreu uma redução entre 1997 e 2007. Isto ocorre porque o componente de participação do capital humano mostra expansão monotônica, uma vez que não depende do tanto do ciclo econômico, sendo mais relacionado a política de universalização da educação, por exemplo. 
Figura 3: A diferença do capital humano na PTF

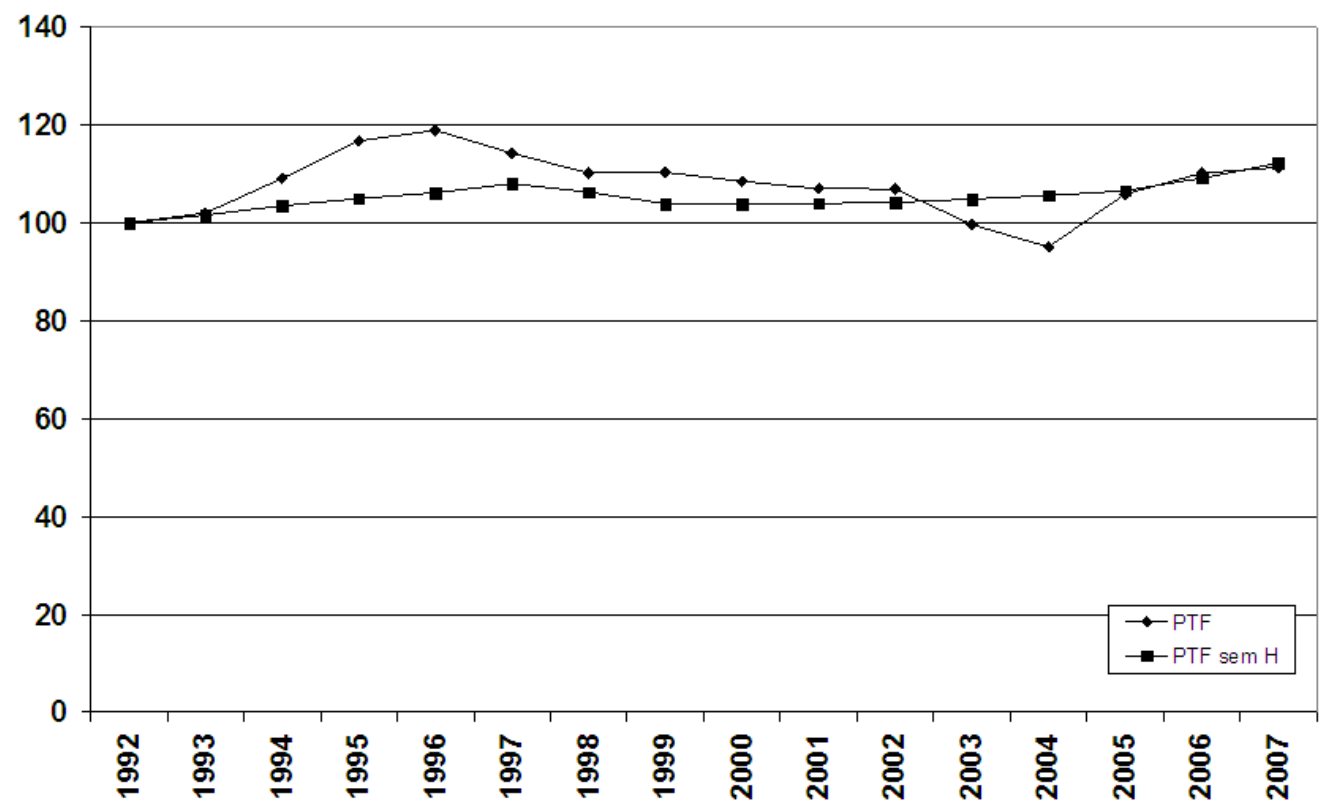

\subsection{Evolução dos fatores de produção}

A Tabela 1 apresenta a evolução de cada uma das variáveis utilizadas neste estudo entre 1992 e 2007: produto, $Y$, produtividade total dos fatores, PTF, estoque de capital fisico ajustado pelo grau de utilização da capacidade, $u K$, capital humano por trabalhador, $H$, e número de horas trabalhadas, $L$.

Como mostra a Tabela 1, o capital humano por trabalhador ficou estagnado entre 1992 e 2007, embora tenha variado ao longo do período. A tabela também documenta um crescimento permanente do número de horas trabalhadas, $L$, e do estoque de capital ajustado pelo grau de utilização da capacidade, $u K$, que crescem em todos os anos estudados.

\subsection{Decomposição do Crescimento}

A Tabela 2 apresenta a decomposição do crescimento para diversos subperíodos. Podemos observar que a PTF contribui somente com 22,9\% do crescimento econômico no Brasil entre 1992 e 2007. No entanto, essa contribuição não foi uniforme ao longo de todo o período. Em particular, a contribuição da PTF foi de quase 50\% no período 1992-1999, mas caiu para apenas 3,2\% entre 1999 e 2007.

É importante ressaltar, no entanto, que no período recente de maior crescimento do produto (entre 2003 e 2007), a PTF apresentou uma elevada taxa de crescimento, de $2,8 \%$ a.a., contribuindo com $62,9 \%$ do crescimento. Caso este fato persista, é possível que a economia brasileira entre em uma nova trajetória de crescimento, baseada não somente na elevação de fatores, mas também, em uma maior produtividade. 
Figura 4: Três medidas de PTF no Brasil

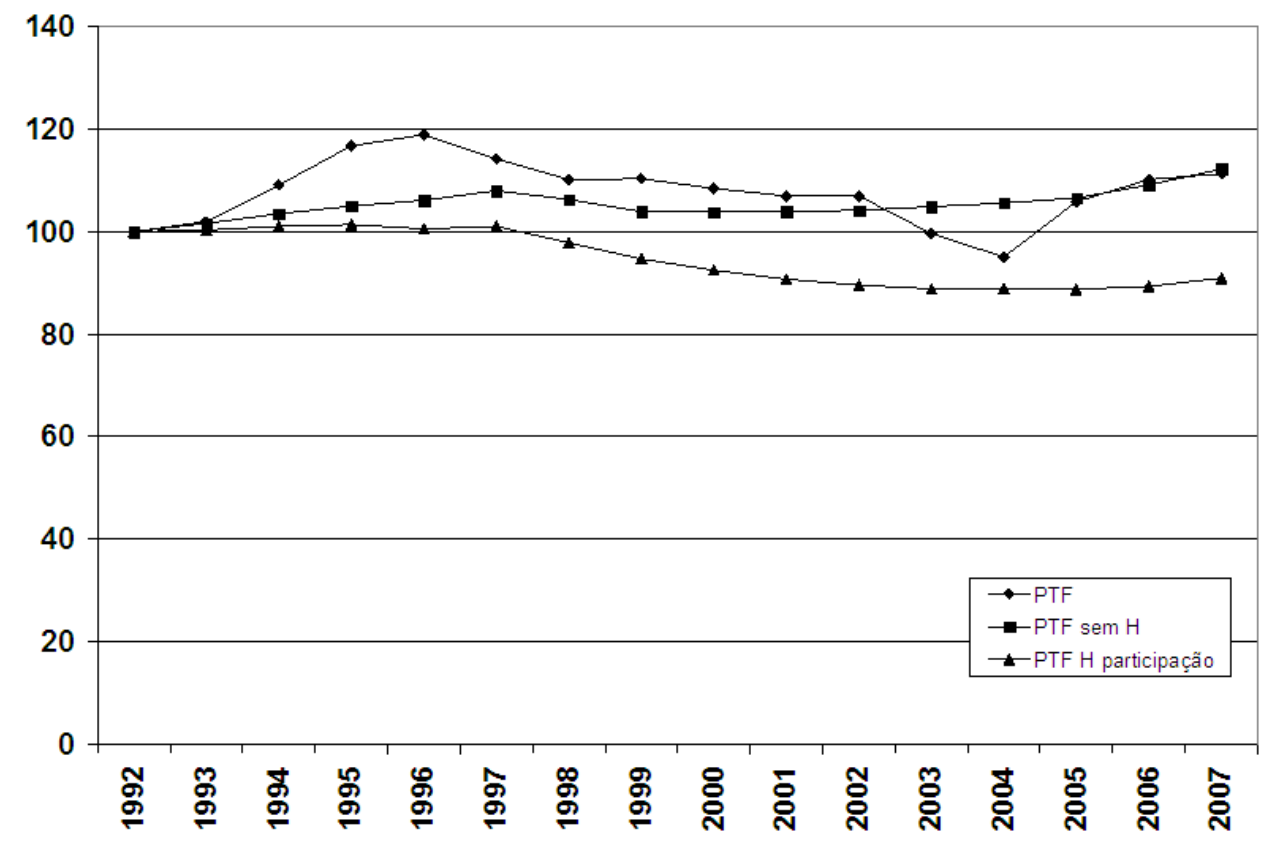

O capital humano, por sua vez, possui uma contribuição praticamente nula entre 1992 e 2007 . No entanto, sua contribuição para o crescimento varia de forma significativa entre subperíodos. Isto ocorre devido à variância do retorno de mercado do capital humano, que oscila com o ciclo econômico e com as condições do mercado de trabalho.

O estoque de capital físico ajustado pelo grau de utilização da capacidade e o número de horas trabalhadas foram os principais responsáveis pelo crescimento entre 1992 e 2007, contribuindo, respectivamente, com $38,4 \%$ e $37,0 \%$ do crescimento no período. Além disso, esses fatores de produção contribuíram de forma positiva para o crescimento em todos os subperíodos estudados.

A Tabela 3 faz uma análise similar à realizada na Tabela 2, com a diferença de que a PTF foi calculada sem incluir o capital humano na função de produção. Devido à estagnação do capital humano no período entre 1992 e 2007, a decomposição com e sem o capital humano apresenta resultados similares para o período como um todo, embora se verifiquem diferenças significativas em alguns subperíodos.

Uma última análise de decomposição do crescimento é realizada com base em uma metodologia onde considera-se somente o componente de participação do capital humano (Hp), como reportado na Tabela 4. Como mostra a tabela, nesse caso o capital humano é responsável por uma parcela expressiva do crescimento (45\%) entre 1992 e 2007, enquanto a PTF passa a ter uma queda no período. 
Tabela 1: Evolução da PTF e dos fatores de produção

\begin{tabular}{llllll}
\hline & $Y$ & $P T F$ & $u K$ & $H$ & $L$ \\
\hline 1992 & 100,0 & 100,0 & 100,0 & 100,0 & 100,0 \\
1993 & 104,7 & 102,2 & 101,5 & 99,4 & 100,3 \\
1994 & 110,2 & 109,1 & 103,3 & 91,6 & 102,4 \\
1995 & 115,1 & 116,7 & 105,7 & 83,8 & 104,5 \\
1996 & 117,6 & 118,9 & 108,5 & 82,7 & 104,9 \\
1997 & 121,6 & 114,2 & 111,4 & 91,1 & 105,1 \\
1998 & 121,6 & 110,2 & 114,6 & 94,2 & 106,3 \\
1999 & 121,9 & 110,3 & 117,8 & 90,5 & 109,6 \\
2000 & 127,2 & 108,5 & 120,3 & 92,9 & 112,7 \\
2001 & 128,8 & 107,0 & 123,0 & 95,4 & 115,9 \\
2002 & 132,3 & 106,9 & 125,6 & 95,7 & 118,4 \\
2003 & 133,8 & 99,6 & 127,8 & 108,9 & 119,9 \\
2004 & 141,4 & 95,0 & 129,6 & 119,1 & 125,2 \\
2005 & 145,9 & 105,9 & 131,9 & 101,1 & 128,1 \\
2006 & 151,4 & 110,2 & 134,4 & 98,4 & 129,9 \\
2007 & 159,5 & 111,3 & 137,5 & 101,4 & 133,4 \\
\hline
\end{tabular}

Tabela 2: Decomposição do crescimento

\begin{tabular}{llllll}
\hline & $Y$ & $P T F$ & $u K$ & $H$ & $L$ \\
\hline $1992-1995$ & 0,047 & 0,052 & 0,022 & $-0,035$ & 0,009 \\
& & $(109,9)$ & $(46,6)$ & $(-75,4)$ & $(18,9)$ \\
$1995-1999$ & 0,014 & $-0,014$ & 0,010 & 0,012 & 0,007 \\
& & $(-98,5)$ & $(68,3)$ & $(80,6)$ & $(49,5)$ \\
$1999-2003$ & 0,023 & $-0,026$ & 0,007 & 0,028 & 0,013 \\
& & $(-109,9)$ & $(32,3)$ & $(119,8)$ & $(57,8)$ \\
$2003-2007$ & 0,044 & 0,028 & 0,011 & $-0,011$ & 0,016 \\
& & $(62,9)$ & $(25,2)$ & $(-24,5)$ & $(36,4)$ \\
$1992-1999$ & 0,028 & 0,014 & 0,015 & $-0,009$ & 0,008 \\
& & $(49,5)$ & $(52,9)$ & $(-30,2)$ & $(27,8)$ \\
$1999-2007$ & 0,034 & 0,001 & 0,009 & 0,009 & 0,015 \\
& & $(3,2)$ & $(27,7)$ & $(25,3)$ & $(43,8)$ \\
$1992-2007$ & 0,031 & 0,007 & 0,012 & 0,001 & 0,012 \\
& & $(22,9)$ & $(38,4)$ & $(1,7)$ & $(37,0)$ \\
\hline
\end{tabular}

Nota: Os termos em parênteses representam a contribuição percentual

de cada fator para o crescimento no respectivo período. 
Tabela 3: Decomposição do crescimento sem $H$

\begin{tabular}{lllll}
\hline & $Y$ & $P T F$ & $u K$ & $L$ \\
\hline $1992-1995$ & 0,047 & 0,016 & 0,022 & 0,009 \\
& & $(34,5)$ & $(46,6)$ & $(18,9)$ \\
\hline $1995-1999$ & 0,014 & $-0,003$ & 0,010 & 0,007 \\
& & $(-17,8)$ & $(68,3)$ & $(49,5)$ \\
\hline $1999-2003$ & 0,023 & 0,002 & 0,007 & 0,013 \\
& & $(9,9)$ & $(32,3)$ & $(57,8)$ \\
\hline $2003-2007$ & 0,044 & 0,017 & 0,011 & 0,016 \\
& & $(38,4)$ & $(25,2)$ & $(36,4)$ \\
\hline $1992-1999$ & 0,028 & 0,005 & 0,015 & 0,008 \\
& & $(19,3)$ & $(52,9)$ & $(27,8)$ \\
\hline $1999-2007$ & 0,034 & 0,010 & 0,009 & 0,015 \\
& & $(28,6)$ & $(27,7)$ & $(43,8)$ \\
\hline $1992-2007$ & 0,031 & 0,008 & 0,012 & 0,012 \\
& & $(24,6)$ & $(38,4)$ & $(37,0)$ \\
\hline
\end{tabular}

Nota: Os termos em parênteses representam a contribuição

percentual de cada fator para o crescimento no respectivo período.

Tabela 4: Decomposição do crescimento com $H^{P}$

\begin{tabular}{llllll}
\hline & $Y$ & $P T F$ & $u K$ & $H^{P}$ & $L$ \\
\hline $1992-1995$ & 0,047 & 0,005 & 0,022 & 0,012 & 0,009 \\
& & $(9,8)$ & $(46,6)$ & $(24,6)$ & $(18,9)$ \\
\hline $1995-1999$ & 0,014 & $-0,017$ & 0,010 & 0,015 & 0,007 \\
& & $(-119,9)$ & $(68,3)$ & $(102,1)$ & $(49,5)$ \\
\hline $1999-2003$ & 0,023 & $-0,016$ & 0,007 & 0,018 & 0,013 \\
& & $(-68,6)$ & $(32,3)$ & $(78,5)$ & $(57,8)$ \\
\hline $2003-2007$ & 0,044 & 0,006 & 0,011 & 0,011 & 0,016 \\
& & $(13,3)$ & $(25,2)$ & $(25,1)$ & $(36,4)$ \\
\hline $1992-1999$ & 0,028 & $-0,008$ & 0,015 & 0,013 & 0,008 \\
& & $(-27,8)$ & $(52,9)$ & $(47,1)$ & $(27,8)$ \\
\hline $1999-2007$ & 0,034 & $-0,005$ & 0,009 & 0,015 & 0,015 \\
& & $(-15,0)$ & $(27,7)$ & $(43,5)$ & $(43,8)$ \\
\hline $1992-2007$ & 0,031 & $-0,006$ & 0,012 & 0,014 & 0,012 \\
& & $(-20,4)$ & $(38,4)$ & $(45,0)$ & $(37,0)$ \\
\hline Nota: 0s termos em parênteses representam a contribuição percentual & \\
de cada fator para o crescimento no respectivo período. & & \\
\hline
\end{tabular}




\subsection{Decomposição do capital humano}

Conforme analisado na Seção 2, podemos decompor o capital humano em dois componentes, que capturam as dimensões de produtividade e participação do capital humano, respectivamente. A Tabela 5 apresenta os resultados para essa decomposição.

Tabela 5: Componentes do capital humano

\begin{tabular}{llcc}
\hline & $H$ & $H^{\text {produtividade }}$ & $H^{\text {participą̧ão }}$ \\
\hline 1992 & 100 & 100 & 100 \\
1993 & 99 & 97 & 102 \\
1994 & 92 & 88 & 104 \\
1995 & 84 & 79 & 106 \\
1996 & 83 & 76 & 109 \\
1997 & 91 & 82 & 112 \\
1998 & 94 & 82 & 115 \\
1999 & 90 & 77 & 117 \\
2000 & 93 & 77 & 121 \\
2001 & 95 & 76 & 126 \\
2002 & 96 & 74 & 129 \\
2003 & 109 & 83 & 132 \\
2004 & 119 & 89 & 133 \\
2005 & 101 & 75 & 136 \\
2006 & 98 & 71 & 140 \\
2007 & 101 & 71 & 142 \\
\hline
\end{tabular}

Como mostra a Tabela 5, o capital humano decresceu fortemente entre 1992 e 1996. A partir de 1997, este começou a crescer lentamente. Em 2003 e 2004 houve um grande crescimento do capital humano, explicado principalmente pelo crescimento na produtividade. Após o aumento do capital humano observado em 2003 e 2004, nota-se que o capital humano entre 2005 e 2007 está em um nível próximo ao observado em 1992. Outro ponto importante a ser ressaltado é que o fator participação tem crescido sistematicamente, enquanto o fator produtividade decresceu no período como um todo.

As variações relativas no total de horas trabalhadas entre os diversos grupos possuem um aspecto mais inercial do que a do componente produtividade, visto que uma variação na demanda por trabalhadores com mais anos de escolaridade/experiência impacta imediatamente no salário deste grupo, mas a ampliação da oferta depende da disponibilidade de trabalhadores com esta qualificação. Ou seja, o preço responde mais rápido do que a quantidade, visto que a qualificação não pode ser ofertada de forma imediata, elevando-se com tempo e/ou investimento em educação.

Desta forma, o componente de participação está mais relacionado à oferta relativa de trabalhadores com determinado grau de escolaridade/experiência, que tende a variar mais lentamente, enquanto que o elemento produtividade está mais associado às condições de equilíbrio de mercado, que são mais voláteis.

A Tabela 6 apresenta uma decomposição do crescimento do capital humano em diversos subperíodos. Como mostra a tabela, a variação do capital humano por trabalhador entre 1992 e 2007 foi praticamente nula, como resultado da combinação de um aumento da participação e uma igual redução percentual da produtividade ao longo do período. 
Tabela 6: Decomposição do crescimento do capital humano por sub-períodos

\begin{tabular}{cccc}
\hline & Variação & $H^{\text {produtividade }}$ & $H^{\text {participação }}$ \\
\hline $1992-1995$ & $-0,059$ & $-0,078$ & 0,019 \\
& & $(132,2)$ & $(-32,2)$ \\
\hline $1995-1999$ & 0,019 & $-0,005$ & 0,024 \\
& & $(-26,9)$ & $(126,9)$ \\
\hline $1999-2003$ & 0,046 & 0,016 & 0,030 \\
& & $(34,5)$ & $(65,5)$ \\
\hline $2003-2007$ & $-0,018$ & $-0,037$ & 0,019 \\
& & $(204,5)$ & $(-104,5)$ \\
\hline $1992-1999$ & $-0,014$ & $-0,036$ & 0,022 \\
& & $(253,7)$ & $(-153,7)$ \\
\hline $1999-2007$ & 0,014 & $-0,010$ & 0,024 \\
& & $(-71,4)$ & $(171,4)$ \\
\hline $1992-2007$ & 0,001 & $-0,022$ & 0,023 \\
& & $(-2422,0)$ & $(2522,0)$ \\
\hline Nota: Os termos em parênteses representam a contribuição percentual de cada \\
componente para o crescimento do capital humano no respectivo periodo. \\
\hline
\end{tabular}

Além disso, ocorreram flutuações significativas do capital humano em alguns subperíodos. Entre 1992 e 2007, o fator participação eleva-se a cada ano, indicando um aumento do peso de pessoas com maior escolaridade na força de trabalho nesse período. O elemento produtividade, por sua vez, apresenta uma forte tendência de queda entre 1992 e 2007, com um período de reversão entre 1999 e 2003.

As tabelas abaixo apresentam a contribuição marginal das diversas categorias de escolaridade e experiência para a variação do capital humano. Nas Tabelas 7 e 8 encontram-se a contribuição marginal da educação sobre a produtividade e a participação, ${ }^{6}$ enquanto que as Tabelas 9 e 10 apresentam a contribuição marginal da experiência sobre os dois fatores que compõem o capital humano.

Na Tabela 7 pode-se observar que o grupo de trabalhadores com ensino médio (categoria 11) é o maior responsável pela redução da produtividade do capital humano entre 1992 e 2007 (35,6\% da queda da produtividade total). Os trabalhadores com ensino fundamental completo também contribuem de forma substancial para a redução da produtividade do capital humano, explicando $19,1 \%$ da queda ocorrida entre 1992 e 2007. Outro ponto que deve ser ressaltado é a contribuição positiva do capital humano dos trabalhadores com ensino fundamental de $1^{a}$ a $4^{a}$ série incompletos entre 1999 e 2007.

A Tabela 8 apresenta os efeitos marginais da educação na variação do componente de participação do capital humano. A tabela ilustra que a mão-de-obra brasileira está ficando mais escolarizada, uma vez que a participação de trabalhadores com escolaridade inferior ao ensino fundamental completo tem reduzido a sua participação no mercado. Em contrapartida, ocorreu a ampliação da participação nas horas trabalhadas de grupos com maior escolaridade, em particular, com ensino fundamental, médio e superior completo.

\footnotetext{
${ }^{6}$ As categorias de educação são definidas da seguinte forma: 0 - analfabetos e com $1^{o}$ ciclo do ensino fundamental incompleto(inferior a quatro anos de estudo), $4-1^{\circ}$ ciclo do ensino fundamental completo (escolaridade igual ou maior que quatro e inferior a oito anos de estudo), $8-2^{\circ}$ ciclo do ensino fundamental completo (igual ou maior que oito e inferior a onze anos de estudo), 11 - ensino médio completo (igual ou maior que onze e inferior a quinze anos de estudo) e 15 - superior completo (quinze ou mais anos de estudo).
} 
Tabela 7: Efeito marginal da educação na produtividade (em \%)

\begin{tabular}{ccccccc}
\hline & Total & 0 & 4 & 8 & 11 & 15 \\
\hline $1992-1999$ & $-3,62$ & $-0,90$ & $-1,21$ & $-0,65$ & $-0,71$ & $-0,14$ \\
& & $(25)$ & $(33,5)$ & $(17,8)$ & $(19,7)$ & $(4)$ \\
\hline $1999-2007$ & $-1,01$ & 0,18 & $-0,06$ & $-0,20$ & $-0,69$ & $-0,25$ \\
& & $(-18,1)$ & $(5,5)$ & $(19,9)$ & $(68,2)$ & $(24,4)$ \\
\hline $1992-2007$ & $-2,20$ & $-0,27$ & $-0,54$ & $-0,42$ & $-0,78$ & $-0,19$ \\
& & $(12,1)$ & $(24,4)$ & $(19,1)$ & $(35,6)$ & $(8,9)$ \\
\hline
\end{tabular}

Nota: Os termos em parênteses representam a contribuição de cada nível de educação

para a variação total.

Tabela 8: Efeito marginal da educação na participação (em \%)

\begin{tabular}{lcccccc}
\hline & Total & 0 & 4 & 8 & 11 & 15 \\
\hline $1992-1999$ & 2,19 & $-0,81$ & $-0,01$ & 0,72 & 1,53 & 0,77 \\
& & $(-37,0)$ & $(-0,6)$ & $(33,0)$ & $(69,6)$ & $(35,0)$ \\
\hline $1999-2007$ & 2,43 & $-0,75$ & $-0,70$ & 0,39 & 2,66 & 0,83 \\
& & $(-30,7)$ & $(-28,6)$ & $(15,9)$ & $(109,4)$ & $(34,0)$ \\
\hline $1992-2007$ & 2,29 & $-0,84$ & $-0,44$ & 0,56 & 2,21 & 0,79 \\
& & $(-36,5)$ & $(-19,1)$ & $(24,2)$ & $(96,7)$ & $(34,7)$ \\
\hline \multicolumn{7}{l}{ Nota: Os termos em parênteses representam a contribuição de cada nível de educação } \\
para a variação total.
\end{tabular}

A Tabela 8 também mostra que o grupo de trabalhadores com ensino médio completo foi o que teve a maior contribuição para o aumento do componente de participação do capital humano. Essa evidência é consistente com a contribuição negativa desse grupo para o aumento da produtividade, conforme mostrado na Tabela 7. Esta maior oferta de trabalhadores com pelo menos ensino médio reduz o ganho desse grupo, já que reduz a escassez de mão-de-obra com estas características. O mesmo ocorre para o grupo de trabalhadores com ensino fundamental completo.

As Tabelas 9 e 10 apresentam o efeito marginal da experiência da mão-de-obra nos componentes de produtividade e participação, respectivamente. A Tabela 9 documenta que todos os níveis de experiência contribuíram para a queda na produtividade, principalmente no período 1992-1999, no qual a queda é maior para todos os níveis de experiência.

Nota-se, a partir da Tabela 10, que a experiência contribui de forma positiva para a elevação do fator participação no período 1992-2007. Somente em 3 das 21 células o efeito marginal da experiência é negativo sobre a participação. Mais uma vez, o maior efeito da experiência ocorre para os trabalhadores mais experientes. Este resultado indica, de certa forma, que as pessoas estão ofertando mais trabalho ao longo do período estudado, o que eleva a participação dos mais experientes na economia, como pode ser observado nas últimas 3 colunas da Tabela 10. 
Tabela 9: Efeito marginal da experiência na produtividade (em \%)

\begin{tabular}{lcccccccc}
\hline & Total & 1 & 2 & 3 & 4 & 5 & 6 & 7 \\
\hline $1992-1999$ & $-3,62$ & $-0,40$ & $-0,50$ & $-0,47$ & $-0,42$ & $-0,45$ & $-0,41$ & $-0,97$ \\
& & $(11)$ & $(14)$ & $(13)$ & $(12)$ & $(12)$ & $(11)$ & $(27)$ \\
\hline $1999-2007$ & $-1,01$ & $-0,04$ & $-0,22$ & $-0,22$ & $-0,19$ & $-0,15$ & $-0,12$ & $-0,07$ \\
& & $(2)$ & $(23)$ & $(22)$ & $(19)$ & $(15)$ & $(12)$ & $(6)$ \\
\hline $1992-2007$ & $-2,20$ & $-0,20$ & $-0,38$ & $-0,33$ & $-0,28$ & $-0,28$ & $-0,25$ & $-0,49$ \\
& & $(9)$ & $(18)$ & $(15)$ & $(13)$ & $(12)$ & $(11)$ & $(22)$ \\
\hline \\
Nota: Os termos em parênteses representam a contribuição de cada nivel de experiência para a \\
variação total.
\end{tabular}

Tabela 10: Efeito marginal da experiência na participação (em \%)

\begin{tabular}{ccccccccc}
\hline & Total & 1 & 2 & 3 & 4 & 5 & 6 & 7 \\
\hline $1992-1999$ & 2,19 & 0,44 & $-0,07$ & $-0,09$ & 0,29 & 0,51 & 0,48 & 0,64 \\
& & $(20)$ & $(-3)$ & $(-4)$ & $(13)$ & $(23)$ & $(22)$ & $(29)$ \\
\hline $1999-2007$ & 2,43 & 0,06 & 0,52 & 0,21 & $-0,05$ & 0,20 & 0,37 & 1,12 \\
& & $(3)$ & $(21)$ & $(8)$ & $(-2)$ & $(8)$ & $(15)$ & $(46)$ \\
\hline $1992-2007$ & 2,29 & 0,22 & 0,27 & 0,06 & 0,09 & 0,34 & 0,41 & 0,89 \\
& & $(10)$ & $(12)$ & $(3)$ & $(4)$ & $(15)$ & $(18)$ & $(39)$ \\
\hline
\end{tabular}

Nota: Os termos em parênteses representam a contribuição de cada nível de experiência para

a variação total. 


\section{ANÁLISE DE OFERTA E DEMANDA}

\subsection{Teoria}

As seções anteriores apresentaram o cálculo do capital humano e a sua decomposição entre produtividade e participação. Esta seção busca identificar qual foi o efeito dominante (oferta ou demanda) na remuneração destes fatores no mercado de trabalho. A análise segue a metodologia utilizada por Katz e Murphy (1992). ${ }^{7}$ Segue de (1) que os serviços totais do trabalho são dados por $H L$. Supõe-se:

$$
H L=G\left(H_{1}, H_{2}, \ldots\right) \text {, }
$$

em que $H_{i}$ é o emprego de cada uma das 35 categorias de capital humano e $G$ é um agregador côncavo e homogêneo do primeiro grau que associa os serviços totais de trabalho ao emprego das quantidades $H_{h}$. Logo, a demanda por cada um dos tipos de capital humano será dada por:

$$
H_{i, t}^{D}=D_{i, t}\left(w_{1 t}^{h}, w_{2 t}^{h}, \ldots, w_{35 t}^{h}, z_{t}\right)
$$

em que $H_{t}^{D}$ é a demanda por capital humano $H$ no instante $t, D$ é a função de demanda por trabalho com capital humano $H, w_{i t}^{h}$ é a remuneração paga para indivíduos com capital humano $H_{i}$ no instante $t$ e $z_{t}$ são fatores que deslocam a demanda por trabalho. Deslocamentos da demanda podem ser resultado de mudanças tecnológicas, na demanda pelo produto e em outros insumos.

Como a função de produção é côncava, a matriz de preços cruzados na demanda, $D_{w}$, é negativa semi-definida. Diferenciando a equação (17), obtêm-se:

$$
d H_{i, t}^{D}=D_{w} d w_{t}+D_{z} d z_{t}
$$

Utilizando o fato de que $D_{w}$ é negativa semi-definida, temos:

$$
d w_{t}^{\prime}\left(d H_{i, t}^{D}-D_{z} d z_{t}\right)=d w_{t}^{\prime} D_{w} d w_{t} \leq 0
$$

A equação (19) mostra que mudanças nos fatores de oferta (descontadas de deslocamentos da demanda) e mudanças nas remunerações variam negativamente. Desta forma, pode-se testar o efeito caso a demanda seja estável, ou seja, $D_{z} d z_{t}=0$. Neste caso, pode-se analisar, mantendo o fator de demanda fixo, se:

$$
\left(w_{T}^{h}-w_{t}^{h}\right)^{\prime}\left(H_{T}^{h}-H_{t}^{h}\right) \leq 0
$$

Caso a desigualdade (20) seja satisfeita, os dados não rejeitam a hipótese de que o principal fator que afetou a remuneração e a participação do capital humano entre os instantes $t$ e $T$ foi um deslocamento da oferta. Caso esta equação não seja satisfeita, a explicação da variação da remuneração e da participação do capital humano não pode ser explicada completamente com base em variações da oferta, e deve-se buscar uma explicação nos efeitos de demanda.

\subsection{Análise empírica}

Para avaliar se a mudança relativa na oferta do capital humano é o principal fator explicando a dinâmica neste mercado, vamos utilizar o resultado de equilíbrio observado neste mercado: a remuneração e a quantidade de capital humano contratada. A análise é realizada para três períodos distintos: 1992-1999, 1999-2007 e 1992-2007.

\footnotetext{
${ }^{7}$ Ferreira (2004) e Andrade e Menezes-Filho (2005) também fazem uma decomposição da variação dos salários na economia brasileira em movimentos da demanda e oferta de trabalho. Os autores utilizam uma metodologia baseada em Card e Lemieux (2001), que por sua vez é uma extensão da utilizada em Katz e Murphy (1992).
} 
O capital humano continua segmentado nas 35 variáveis dummies com a interação entre os diversos níveis de escolaridade e experiência. A remuneração de cada tipo de capital humano é obtida através dos coeficientes da equação de Mincer $\left(\beta_{j k}\left(h_{j, i}, E_{k, i}\right)\right)$. A quantidade contratada de cada tipo de capital humano é dada pela sua respectiva participação $\left(\varphi_{j k}\left(h_{j, i}, E_{k, i}\right)\right)$, onde $h_{j}$ são os anos de educação e $E_{k}$ os anos de experiência de um trabalhador.

A remuneração de cada tipo de capital humano é calculada em termos reais, para podermos comparar sua evolução ao longo do tempo. ${ }^{8}$ Com base nas remunerações reais e na participação de cada um dos 35 grupos com interação entre anos de educação e experiência, calculou-se o produto interno apresentado na equação (20).

A Tabela 11 mostra que existe uma tendência clara de elevação nos anos de escolaridade da mão-deobra no Brasil, que pode ser observada através da redução da participação de trabalhadores com ensino fundamental de $1^{a}$ a $4^{a}$ série incompleto (linha [0] na tabela) e com ensino fundamental de $5^{a}$ a $8^{a}$ série incompleto (linha [4] na tabela). A contrapartida desta redução de trabalhadores pouco escolarizados é a maior participação de trabalhadores com ensino fundamental de $5^{a}$ a $8^{a}$ série, ensino médio e superior completos.

Tabela 11: Variação da participação no período 1992-2007

\begin{tabular}{cccccccc}
\hline \multicolumn{7}{c}{ Experiência } \\
\hline Educação & 1 & 2 & 3 & 4 & 5 & 6 & 7 \\
\hline 0 & $-0,013$ & $-0,032$ & $-0,027$ & $-0,022$ & $-0,019$ & $-0,017$ & $-0,055$ \\
4 & $-0,024$ & $-0,036$ & $-0,027$ & $-0,017$ & $-0,007$ & $-0,005$ & 0,028 \\
8 & 0,003 & 0,000 & 0,000 & 0,004 & 0,007 & 0,011 & 0,025 \\
11 & 0,026 & 0,036 & 0,024 & 0,018 & 0,021 & 0,021 & 0,031 \\
15 & 0,004 & 0,007 & 0,004 & 0,003 & 0,007 & 0,007 & 0,012 \\
\hline
\end{tabular}

As Tabelas 12, 13 e 14 apresentam os resultados da aplicação da equação (20). Para o subperíodo 1992-1999 (Tabela 12), a oferta explica a maior parte da variação ocorrida para os indivíduos com pelo menos o ensino fundamental de $5^{a}$ a $8^{a}$ série completo (linha [8] na tabela) e para os indivíduos com ensino médio completo. Estes dois grupos observaram uma grande elevação na participação, como pode ser observado na Tabela 11. Dessa forma, o produto interno negativo da equação (20) indica que a grande expansão na participação foi compensada com uma redução na remuneração deste tipo de capital humano. Logo, para estes grupos, o efeito de expansão da oferta explica a maior parte da dinâmica deste insumo.

O efeito da redução da participação dos indivíduos que não possuem sequer o fundamental de $1^{a}$ a $4^{a}$ série (linha [0] na tabela) sobre a sua remuneração depende da sua experiência. A remuneração dos indivíduos mais experientes caiu, enquanto que os salários dos mais novos elevam-se com a redução da oferta. Para os indivíduos com ensino fundamental de $1^{a}$ a $4^{a}$ série, ocorre o oposto, ou seja, os indivíduos menos experientes sofreram uma redução salarial simultânea à queda na participação.

O grupo com ensino superior apresenta uma evidência mista, pois a elevação da oferta está associada a ganhos ou perdas na remuneração, dependendo da categoria de experiência. $O$ valor positivo do produto interno para alguns níveis de experiência indica que, para estas categorias, a elevação da demanda compensou o efeito de expansão da oferta.

A Tabela 13 considera os resultados para o sub-período 1999-2007. Nesta tabela, pode-se observar de forma clara que a elevação na participação de indivíduos com maior escolaridade é o fator que explica a

\footnotetext{
${ }^{8}$ Para isto utilizou-se deflatores com base no ano e mês de coleta dos dados da PNAD.
} 
Tabela 12: Produto interno de (20) no período 1992-1999

\begin{tabular}{cccccccc}
\hline \multicolumn{7}{c}{ Experiência } \\
\hline Educação & 1 & 2 & 3 & 4 & 5 & 6 & 7 \\
\hline 0 & $-0,004$ & $-0,009$ & $-0,002$ & $-0,001$ & 0,001 & 0,003 & 0,003 \\
4 & 0,004 & 0,004 & 0,002 & 0,001 & $-0,001$ & $-0,003$ & $-0,016$ \\
8 & $-0,009$ & $-0,000$ & $-0,000$ & $-0,003$ & $-0,010$ & $-0,016$ & $-0,024$ \\
11 & $-0,026$ & $-0,013$ & $-0,005$ & $-0,020$ & $-0,037$ & $-0,024$ & 0,005 \\
15 & 0,006 & $-0,002$ & 0,002 & 0,004 & $-0,000$ & 0,010 & 0,037 \\
\hline
\end{tabular}

dinâmica da evolução dos salários. Ou seja, com o aumento da oferta de mão-de-obra mais qualificada, a sua remuneração caiu, sinalizando que a elevação na oferta de mão-de-obra mais qualificada não foi acompanhada de uma elevação da demanda pela mesma.

Tabela 13: Produto interno de (20) no período 1999-2007

\begin{tabular}{cccccccc}
\hline \multicolumn{7}{c}{ Experiência } \\
\hline Educação & 1 & 2 & 3 & 4 & 5 & 6 & 7 \\
\hline 0 & $-0,001$ & 0,007 & $-0,011$ & $-0,012$ & $-0,007$ & $-0,012$ & $-0,033$ \\
4 & $-0,010$ & $-0,005$ & $-0,000$ & $-0,008$ & $-0,005$ & $-0,004$ & 0,004 \\
8 & $-0,005$ & 0,000 & $-0,000$ & 0,000 & $-0,000$ & $-0,008$ & $-0,022$ \\
11 & $-0,005$ & $-0,053$ & $-0,070$ & $-0,040$ & $-0,050$ & $-0,067$ & $-0,116$ \\
15 & $-0,001$ & $-0,024$ & $-0,017$ & $-0,001$ & $-0,032$ & $-0,047$ & $-0,070$ \\
\hline
\end{tabular}

A Tabela 14 considera o período 1992-2007. Pode-se observar que a elevação da participação de mãode-obra mais qualificada no mercado de trabalho foi o fator mais importante para explicar a dinâmica de remuneração do capital humano.

Tabela 14: Produto interno de (20) no período 1992-2007

\begin{tabular}{cccccccc}
\hline \multicolumn{7}{c}{ Experiência } \\
\hline Educação & 1 & 2 & 3 & 4 & 5 & 6 & 7 \\
\hline 0 & $-0,010$ & 0,006 & $-0,024$ & $-0,023$ & $-0,012$ & $-0,012$ & $-0,053$ \\
4 & $-0,007$ & $-0,001$ & 0,007 & $-0,008$ & 0,000 & 0,002 & $-0,013$ \\
8 & $-0,001$ & $-0,000$ & $-0,000$ & $-0,007$ & $-0,014$ & $-0,048$ & $-0,110$ \\
11 & $-0,060$ & $-0,138$ & $-0,118$ & $-0,117$ & $-0,172$ & $-0,173$ & $-0,123$ \\
15 & 0,002 & $-0,040$ & $-0,029$ & $-0,027$ & $-0,075$ & $-0,061$ & 0,032 \\
\hline
\end{tabular}

Com base nas tabelas, conclui-se que a queda na remuneração do capital humano decorreu, principalmente, de um aumento da participação no mercado de trabalho de pessoas com mais anos de escolaridade. Desta forma, pode-se concluir que a oferta de mão-de-obra qualificada não impôs restri- 
ções ao crescimento da economia brasileira nos últimos 15 anos, pois sua demanda está crescendo em ritmo inferior ao da oferta.

\section{CONCLUSÃO}

Este artigo teve como objetivo calcular a produtividade total dos fatores da economia brasileira no período entre 1992 e 2007, com ênfase no efeito do capital humano nas medidas de PTF construídas para a economia brasileira. Também realizamos uma decomposição dos fatores que afetaram o crescimento da economia brasileira no período.

A contribuição deste artigo para a literatura reside na construção de um método de cálculo do capital humano que leva em consideração a sua produtividade marginal. Uma vantagem deste método é que ele permite decompor o capital humano em dois fatores distintos, denominados de produtividade e participação. O fator produtividade é o responsável por mensurar o retorno de mercado do capital humano, enquanto o fator participação mede a participação no total de horas trabalhadas de cada grupo de trabalhadores com uma determinada combinação de escolaridade e experiência.

Os resultados mostram que a PTF teve um crescimento de apenas 11,3\% entre 1992 e 2007, contribuindo com cerca de $22,9 \%$ do crescimento do PIB verificado no período. Quando se utiliza uma medida de capital humano baseada apenas no componente de participação, a PTF teve uma redução no período. Outro resultado importante é que o capital humano por trabalhador teve crescimento nulo entre $1992 \mathrm{e}$ 2007. Isso ocorreu porque, embora o componente de participação tenha crescido no período, o componente de produtividade teve uma queda expressiva. A dinâmica na remuneração do capital humano é majoritariamente explicada pelo aumento na oferta de mão-de-obra mais escolarizada. Logo, o capital humano não impôs qualquer restrição ao ritmo de crescimento da economia brasileira, visto que sua oferta cresceu em ritmo superior à sua demanda.

Uma possível interpretação dos resultados é que a expansão quantitativa da educação no Brasil ocorreu em um período no qual, em função do baixo crescimento da PTF, a demanda por trabalho qualificado não acompanhou a expansão da oferta. Em função disso, a contribuição do capital humano para o crescimento econômico do Brasil foi bem menor do que seria de se esperar com base na elevação da escolaridade média verificada no período. Isso sugere que, para que o capital humano tenha um impacto maior no crescimento brasileiro, devem ser implementadas políticas que elevem o retorno da educação, por exemplo, através de uma melhoria da qualidade da educação. De fato, a evidência recente sugere que a relação entre educação e crescimento econômico depende mais da qualidade da educação que de sua quantidade. Esse é um tópico que pretendemos investigar em pesquisas futuras.

\section{BIBLIOGRAFIA}

Andrade, A. \& Menezes-Filho, N. (2005). O papel da oferta de trabalho nos retornos à educação no Brasil. Pesquisa e Planejamento Econômico, 35(2):189-225.

Barbosa Filho, F. H. \& Pessôa, S. A. (2008). Educação e crescimento: O que a evidência empírica e teórica mostra? Mimeo.

Bils, M. \& Klenow, P. J. (2000). Does schooling cause growth? American Economic Review, 90(5):11601183.

Bonelli, R. \& Fonseca, R. (1998). Ganhos de produtividade e de eficiência: Novos resultados para a economia brasileira. Pesquisa e Planejamento Econômico, 28(2):273-314.

Bugarin, M., Ellery Junior, R., Gomes, V., \& Teixeira, A. (2004). From a miracle to a disaster: The Brazilian economy in the last 30 years. Mimeo. 
Card, D. \& Lemieux, T. (2001). Can falling supply explain the rising return to college for younger men? A cohort-based analysis. Quarterly Journal of Economics, 116(2):705-746.

Ferreira, P., Ellery Junior, R., \& Gomes, V. (2008). Produtividade agregada brasileira (1970-2000): Declínio robusto e fraca recuperação. Estudos Econômicos, 38:31-53.

Ferreira, S. (2004). The provision of education and its impacts on college premium in Brazil. Revista Brasileira de Economia, 58(2):211-233.

Gomes, V., Pessôa, S. A., \& Veloso, F. (2003). Evolução da produtividade total dos fatores na economia brasileira: Uma análise comparativa. Pesquisa e Planejamento Econômico, 33(3):389-434.

Hall, R. \& Jones, C. (1999). Why do some countries produce so much more output than others? Quarterly Journal of Economics, 114(1):83-116.

Katz, L. \& Murphy, K. (1992). Changes in relative wages, 1963-1987: Supply and demand factors. Quarterly Journal of Economics, 107(1):35-78.

Krueger, A. B. \& Lindahl, M. (2001). Education for growth: Why and for whom? Journal of Economic Literature, 39(4):1101-1136.

Lange, F. \& Topel, R. (2006). The social value of education and human capital. In Hanushek, E. \& Welch, F., editors, Handbook of the Economics of Education, pages 459-509. North-Holland.

Mincer, J. (1974). Schooling, Experience and Earnings, National Bureau of Economic Research. Columbia University Press.

Pinheiro, A. C., Gill, I. S., Servén, L., \& Thomas, M. R. (2001). Brazilian economic growth, 1900-2000: Lessons and policy implications. Mimeo.

Silva Filho, T. N. (2001). Estimando o produto potencial brasileiro: Uma abordagem de função de produção. Trabalhos para Discussão 17, Banco Central do Brasil.

Topel, R. (1999). Labor markets and economic growth. In Ashenfelter, O. \& Card, D., editors, Handbook of Labor Economics, pages 2943-2984. North-Holland. 